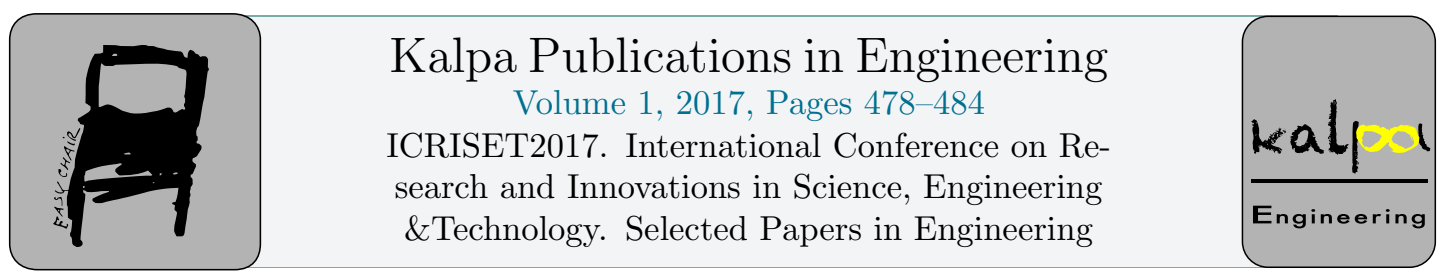

\title{
Theoretical and Experimental Analysis of Monocrystalline Solar Cell
}

\author{
Mahesh Chauhan ${ }^{1}$, Dr.Davit Dhruv ${ }^{2}$,S.A.Solanki ${ }^{3}$, Dr.Nikesh Shah ${ }^{4}$ \\ ${ }^{1}$ M.E. Student, GCET,Electrical Engineering Department,Rajkot,Gujrat India \\ ${ }^{2}$ Asst.Professor Nanotechnology department,VVP Engg College,Rajkot India \\ ${ }^{3}$ Asst.Professor Physics department,VVP Engg College,Rajkot India \\ ${ }^{4}$ Professor Physics department,Saurashtra University,Rajkot India \\ Er.MaheshChauhan@yahoo.com, mailmedavegmail.com, \\ Sapnasolanki44@gmail.com, snikesh@yahoo.com
}

\begin{abstract}
Solar energy is most powerful and trending source among all renewable energy sources. For utility point of view, solar power is available at each place but problem is that the efficiency of solar cell is very low. In addition, the efficiency of solar cell under different atmospheric conditions like different temperature and irradiation, the power we get from the solar cell is different and same as that the efficiency is also changed so for analyzing the behavior of solar cell, we have analyzed mono-crystalline solar cell for different temperature and irradiation and results are taken. For analysis point of view, the mono crystalline solar cell is analyzed into solar simulator under different values of irradiation and temperature and then experimental results for the same are taken. For cross checking the results that we got from the solar simulator, we have done mathematical modelling of solar cell into MATLAB and then the simulated results are taken, the similar kind of results came from the simulation and experimental readings as well.
\end{abstract}

\section{Introduction}

The The photovoltaic cell converts the solar energy into DC electrical energy directly. For making solar cell material used is Silicon, which is having electrons at valance band, so as the solar radiation falls on the material these electrons absorbs energy and goes from valance band to conduction band. These excited electrons of the Silicon now have energy and travel through the material by making electron hole pairs and thus the DC current flows into the material and as a result, the DC Electrical energy is generated and can be fed to the other end of the solar cell [1]

Silicon is the most commonly used material in crystalline as well as polycrystalline solar panel. In polycrystalline solar cell the material used the most is silicon with that Boron is doped on the layer of 
silicon to make it p-type material and at a part of the cell the silicon is doped with phosphorus to make it n-type of material. Intersection between these two layers make the cell junction so when the cell will be exposed to the Sunlight the valance electrons from the p-type region will travel to the n-type region.

Here, the electron-hole pairs are generated because the p-type material is having extra electrons on its valance band similarly the n-type electrons requires that electrons to complete the external band so when the cell will be exposed to the sunlight energy from photon will be transferred to the valance band electrons of p-type material and that electrons will go to conduction band and this empty space of electron is called hole such that the electron-hole will be generated and the electrons will travel through the cell if they have sufficient energy to overcome the electrical field at junction. A single cell is the building block of solar Module and such Modules are used in series and parallel to make a solar PV Array. Solar Module is not sufficient feed electricity to any load so many Solar Modules in series and parallel are used practically for utility point of view.

\section{Factors affecting efficiency of solar cell}

Several factors are there which affect the efficiency of solar cell, the efficiency under standard test condition can't be achieved on field because the value of temperature, illumination and many other factors are changed in external atmosphere. So how these external factors affect the efficiency of solar cell is elaborated below.

1. Cell Temperature: Temperature plays an important factor in determining solar cell efficiency. Photon generation increases with increase in temperature. Simultaneously the reverse saturation current increases rapidly and reduces the band gap that affects both current and voltage but effect on voltage is more pronounce. The open-circuit voltage (Voc) and short-circuit current (Isc) are the two major parameters used to characterize solar cells. With the change in value of cell temperature the simultaneous change in open circuit voltage and current can be seen. As the value of temperature rises the efficiency will be reduced simultaneously. So the cell will be operated at standard temperature which is 25 degree Celsius according to the variation in temperature, we will get change in cell efficiency [2].

2. Energy Conversion Efficiency: Energy Conversion efficiency simply means the percentage of power converted and collected, when a solar cell is connected to an electrical circuit. The amount of energy converted from the sunlight to the Electrical energy can be given by the energy conversion efficiency. There are two methods to improve energy conversion efficiency, one is reduction of the reflection of incident light with an antireflection coating, and the other is optical confinements of incident light with textured surfaces.

3. Solar Irradiance: The overall performance of solar cell varies with varying Irradiance and Temperature with the change in the time of the day the power received from the Sun by the PV panel changes. The voltage and current both being a function of the light falling on the cell, there exists a complex relationship between irradiation and output power. At lower irradiation levels these mechanisms show an increasing percentage of the total power generated. Too much irradiation causes saturation of cells, and the number of free electrons or their mobility decreases greatly [3]. The irradiance and spectral distribution vary greatly from day to day. Resulting into flow of current. The PV cell current is strongly dependent on the solar radiation. 


\section{Simulation and results}

\subsection{Mathematical Modelling}

For doing mathematical modelling of solar cell, The Solar cell is simulated into MATLAB. By implementing the equations of solar cell and by putting the value of different parameters from the manufacturer. Also graph of $\mathrm{P}-\mathrm{V}$ and $\mathrm{I}-\mathrm{V}$ are taken from the simulation for comparison with the experimental results.

\subsection{Equation to be Modelled:}

1. Module Reverse Saturation Current [7]:

$$
\operatorname{Irr}=\frac{I s c r}{e^{\left\{\left(q * \frac{V O C}{K} * N s * A * T r k\right)-1\right]}}
$$

2. Module Photo Current [7]:

$$
I d=\operatorname{Irr} *\left(\frac{T a k}{T r k}\right)^{3} * e^{\wedge}\left[\left(E g * \frac{q}{K} * A\right) *\left(\frac{1}{T r k}-1 / \text { Tak }\right)\right.
$$

3. Module saturation current varying with cell Temperature[7]:

$$
I p v=[I s c r+(K i *(T a k-T r k))] *\left(\frac{S}{1000}\right)
$$

4. Current output of PV Module [7]:

$$
I o=N p * I p h-N p * I d *\left[e^{\left\{\left(\frac{q}{N s} * A * K * T a k\right) *(V o+I o * R s)\right\}}-1\right]
$$

\subsection{Abbreviations:}

- $\quad$ Io = Output current of PV modual

- $\quad \mathrm{Vo}=$ Output voltage of PV modual

- $\quad \operatorname{Trk}=$ Reference temp of modual in $\mathrm{K}$

- $\quad$ Tak $=$ Operating temp of modual in $\mathrm{K}$

- $\mathrm{S}=$ Illumination in $\mathrm{W} / \mathrm{cm} 2$

- $\mathrm{Q}=$ Electron Charge $=1.6^{*} 10^{\wedge}(-19)$

- $\mathrm{A}=$ Identity Factor $=1.3$

- $\mathrm{K}=$ Boltzmann constant $=1.3805^{*} 10^{\wedge}(-23) \mathrm{J} / \mathrm{K}$

- $\mathrm{Eg}=$ Band Gap of $\mathrm{Si}=1.12 \mathrm{eV}$

- $\quad$ Iscr $=$ Short circuit current at $25 \mathrm{C} \& \mathrm{~S}=1000$

- $\quad \mathrm{Ns}=$ No of sells in series

- $\quad \mathrm{Np}=$ No of cell in parallel 
- $\mathrm{Ki}=$ Short circuit temperature coefficient at Iscr $=0.0013 \mathrm{~A} / \mathrm{C}$

- $\quad \mathrm{Rs}=$ Series resistance of PV modual

- $\quad \mathrm{Ipv}=$ Light generated current of PV Modual

- $\quad$ Id = Saturation current of PV modual

\subsection{Simulation in MATLAB with Subsystems:}

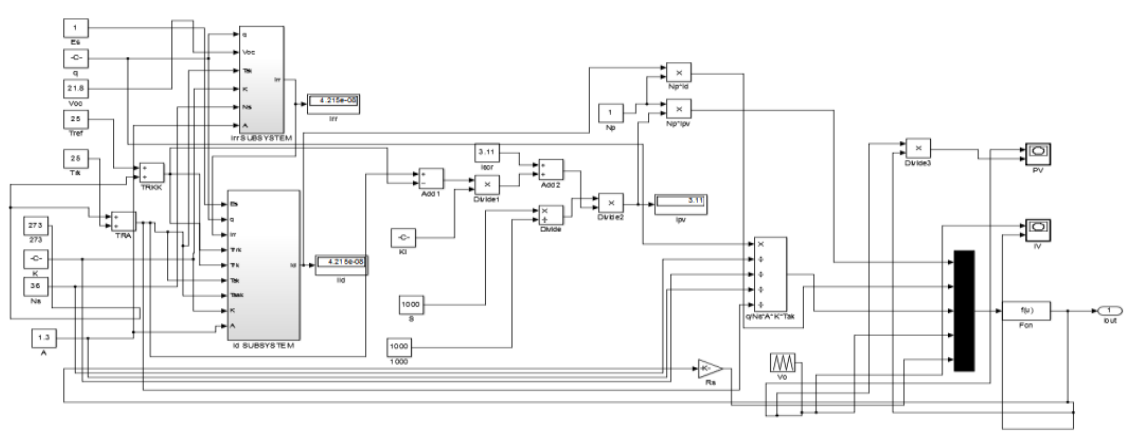

Figure 3.1 Modelling of Solar Cell in MATLAB

\subsection{P-V and I-V curve from Simulation:}

From the model given above the solar cell is simulated into MATLAB and for that the PV and IV curves are taken from the XY scope which are given below. These curves will be used to be compared with the results of experimental analysis result.

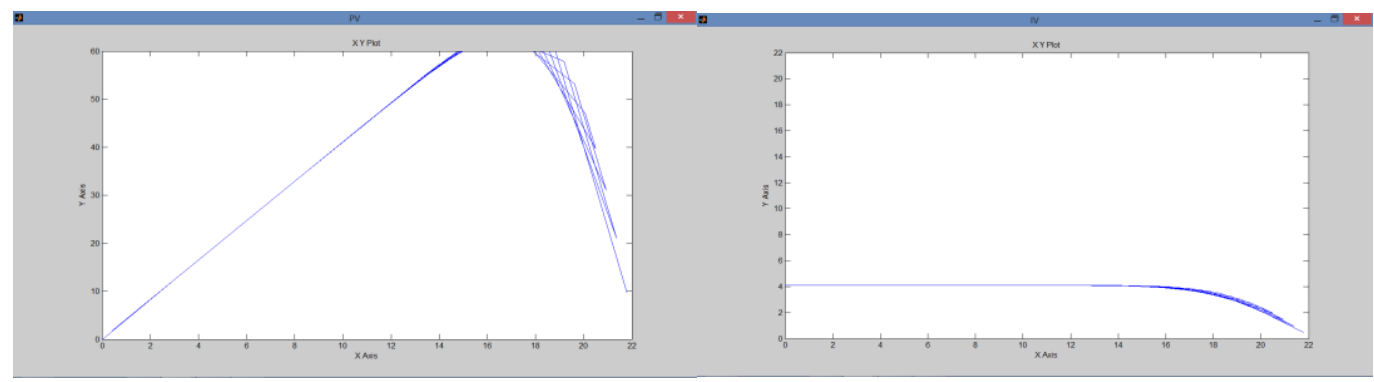

Figure 3.2 P-V and I-V Curve of Solar cell

\section{Experimental Analysis and Results}

For analyzing the behavior of monocrystalline solar cell, I have used c-Si monocrystalline solar panel of $4 \mathrm{~cm} * 4 \mathrm{~cm}$ size having output of 2 Volt. For applying irradiation to the solar cell and to measure the reading of voltage, current, and temperature different equipment are used which are given below. Also the results of the change in cell temperature and irradiation are also measured and for that the graphs for Current, Voltage and Power are given for different values of irradiation and temperature. 


\subsection{Result with change in Irradiance:}

For analyzing the behavior of solar cell under different irradiation, we have used four filters for having different values of irradiation, also we can use light dimmer but here we have applied filters which are specially designed to give specific amount of irradiation to the solar cell. The irradiation from two halogen lamp without any filter is around $1200 \mathrm{~W} / \mathrm{m}^{\wedge} 2$ and by using different filters the value of irradiation will be changed. Filter 1 will give $1000 \mathrm{~W} / \mathrm{m}^{\wedge} 2$, Filter 2 will give $800 \mathrm{~W} / \mathrm{m}^{\wedge} 2$, Filter 3 will give $600 \mathrm{~W} / \mathrm{m}^{\wedge} 2$, simultaneously filter 4 will give irradiation of $400 \mathrm{~W} / \mathrm{m}^{\wedge} 2$.

For different values of irradiation the generated voltage and current are measured and graph is plotted into MATLAB with the help of experimental data. Graphs for all these data are given below.

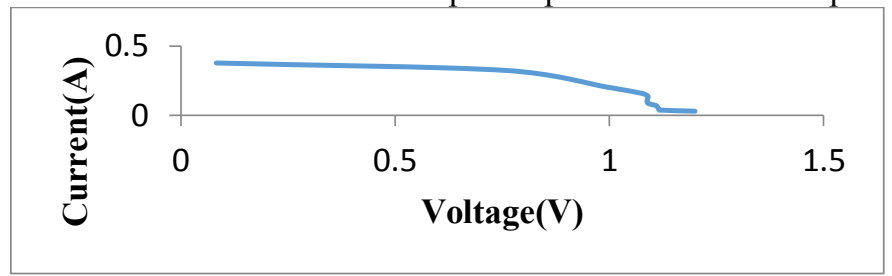

Figure 4.1 I-V curve for $1200 \frac{W}{m^{2}}$

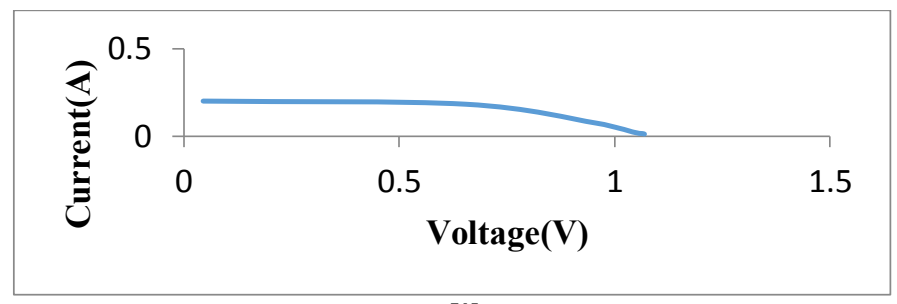

Figure 4.2 I-V curve for $1000 \frac{W}{m^{2}}$

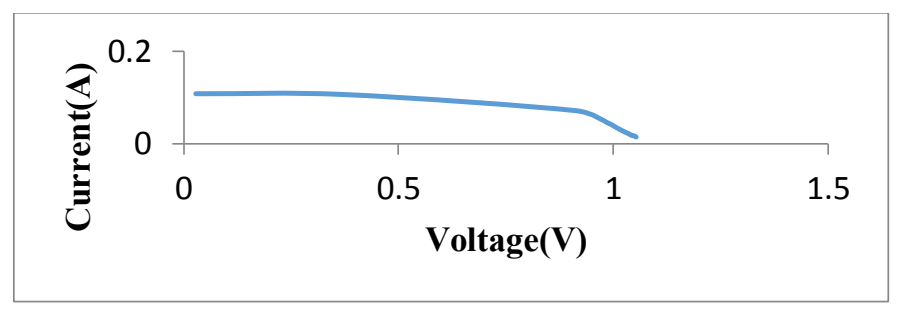

Figure 4.3 I-V curve for $800 \frac{W}{m^{2}}$

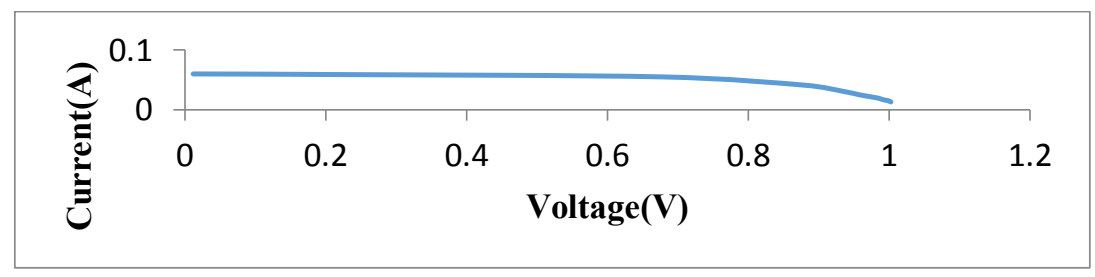

Figure 4.4 I-V curve for $600 \frac{W}{m^{2}}$ 


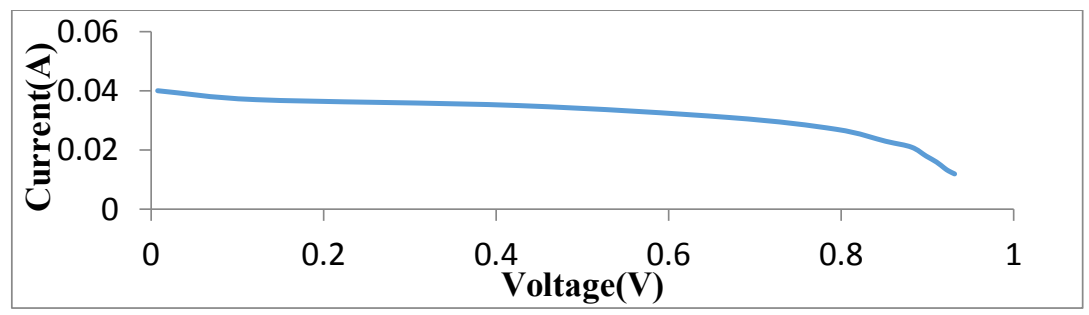

Figure 4.5 I-V curve for $400 \frac{W}{m^{2}}$

\subsection{Result with change in Temperature:}

Temperature plays an important factor in determining solar cell efficiency. As the temperature increases, the rate of the photon generation increases. Band gap will be reduced and the reverse saturation current will increase rapidly. Hence, this leads to marginal changes in the current but major changes in voltage for different values of temperature [4] the voltage and current will be measured. The readings and corresponding graphs for different temperature are given below. From the graph, we can see that the variation of voltage is there with the change in cell temperature.

Variation in temperature is measured with the help of IC-LM35 which is a temperature sensor which will give $10 \mathrm{mV}$ rise in output $\mathrm{DC}$ voltage for 1 degree Celsius rise in temperature. So first the reference temperature is measured and then the change in output voltage will be noted that will give the change in temperature simultaneously the variation in voltage and current will also be measured. The change in the current from the panel is generally very less so that graph of variation of voltage with temperature is given here.

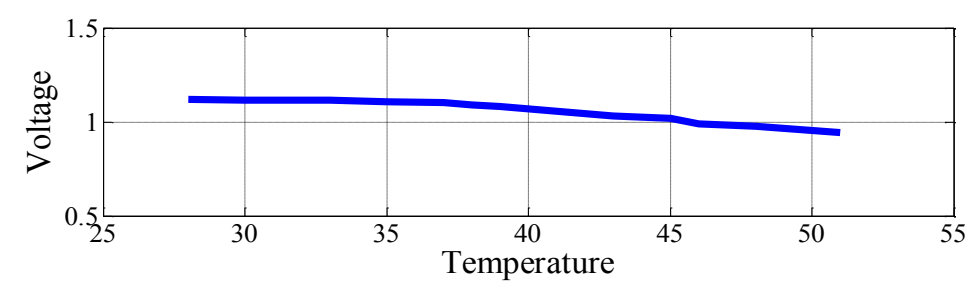

Figure 4.6 T-V graph with Rs $=110 \Omega$

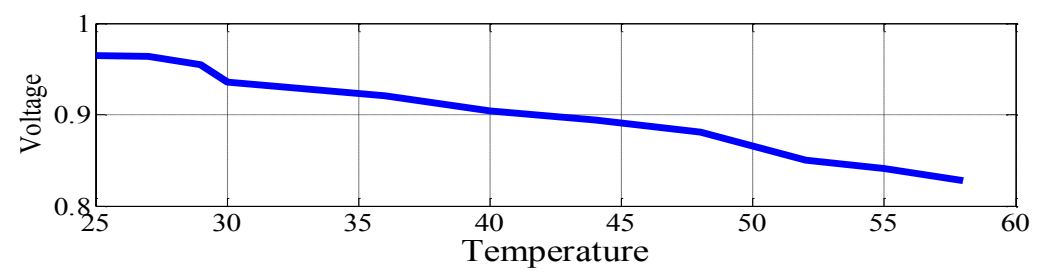

Figure 4.7 T-V graph with Rs $=50 \Omega$

From the graph and readings shown above we can see that the value of voltage decrease with increase in temperature and in case of current we can see a slight change in value of current. Considering 
the behavior of solar cell under standard test condition temperature of 25 degree Celsius is decided to be there for operating the cell in its predefined standard behavior, for use of same panel for different atmospheric condition the change in output voltage and current can be seen into the graph given. Submitting the Article for Reviewing

It is up to your conference in what format you submit your article. Most likely, they will simply ask for a PDF file. You will see the list of accepted file types on the EasyChair submission page. Nonetheless, if your conference will publish proceedings as an EPiC or a Kalpa volume, we recommend that you use the EasyChair style for the submission too. The reason is that otherwise, if your paper is accepted for the proceedings, you will have to reformat it using the EasyChair style and this can be time-consuming. If you need to submit a PDF document, you can convert your docx document to PDF by choosing File->Save As... in your Word menu.

\section{Conclusion}

After working on the mono crystalline solar cell, the simulation result and Experimental analysis proves that, the Temperature and illumination change affects the efficiency of solar cell. With increase in temperature the cell output voltage decrease and in case of irradiation, the output voltage and efficiency of solar cell increases simultaneously with increase in illumination.

\section{References}

1. Shruti Sharma, KamleshcKumar Jain, Ashutosh Sharma "Solar Cells: In Research and Application-A Review." scientific Research Publication. 2015, 6, 1145-1155.

2. Furkan Dincer, Mehmet Emin Meral, "Critical Factors that Affecting Efficiency of Solar Cells.” Scientific research Publication. 2010, 1, 47-50.

3. Gayatri Nanda, Ritesh Dash, Dr.Sarat Chandra Swain, Dr.Rajesh Kumar, "A Comparative Study on Different Types of PV Modules and Their Optimization for Increasing the Efficiency Part-1.” International Conference on Computational Intelligence \& Communication Technology, 2016.

4. N.H.Zaini, M.Z.Ab Kadir, M. Izadi, N.I. Ahmd, M.A.M. Radzi and N. Azis "The Effect of Temperature on a Mono-crystalline Solar PV Panel.” IEEE, 2015.

5. Tarak Salmi, Mounir Bouzguenda, Adel Gastli, Ahmed Masmoudi "MATLAB/Simulink Based Modelling of Solar Photovoltaic Cell." International Journal of Renewable Energy and Research. 2012, Vol-2, No-2

6. George Anglov, Rostislav Rusev, Anna Andonova, Marin Hristov "Behavior Modelling of Polycrystalline Module ET-P660230WW.” IEEE, 2013, 978-1-4799-0036-7/13.

7. N.PandiaRajan and Rangnath Muthu "Mathematical Modelling of Photovoltaic Module with Simulink." IEEE. 2011, 978-1-61284-379-7/11. 